\title{
Modeling the Social Factors Affecting Students' Satisfaction with Online Learning: A Structural Equation Modeling Approach
}

\author{
Abdulhameed Rakan Alenezi (iD \\ Department of Instructional Technology, Faculty of Education, Jouf University, Sakaka, Saudi Arabia \\ Correspondence should be addressed to Abdulhameed Rakan Alenezi; a.alenezi@hotmail.com
}

Received 19 November 2021; Revised 12 December 2021; Accepted 28 December 2021; Published 21 January 2022

Academic Editor: Xiao-Guang Yue

Copyright (c) 2022 Abdulhameed Rakan Alenezi. This is an open access article distributed under the Creative Commons Attribution License, which permits unrestricted use, distribution, and reproduction in any medium, provided the original work is properly cited.

\begin{abstract}
While online learning has always faced criticism regarding social issues such as the lack of engagement, interaction, and communication, the COVID-19 social distancing has increased the public's concern and criticism. Therefore, the purpose of this research was to investigate and model the social factors affecting students' satisfaction with online learning. The proposed research model was constructed based on the extensive review of relevant literature to determine the critical social factors examined and validated in this research. The data were collected from a total of 258 students using a quantitative method approach. A structural equation modeling technique was utilized in analyzing the obtained data. The findings of the study reveal that all proposed social factors namely social presence, social interaction, social space, social identity, social influence, and social support were found to significantly affect the students' satisfaction with online learning. The examined factors account for about $56 \%$ of the total variance in students' satisfaction. Several suggestions and recommendations are provided in line with study limitations.
\end{abstract}

\section{Introduction}

Online learning has risen in popularity in recent years, as technology has been incorporated into all levels of education and training. Consequently, scholars have been looking for methods to enhance its efficacy [1]. Online learning has been marketed as being less expensive and more convenient than conventional educational settings and offering more possibilities for students to complete their education. Learning is considered to be a social process [2], and online learning involves all of the social elements and factors at the heart of the learning process $[3,4]$. Social presence, interaction, space, and connectivity are all considered important determinants of online learning success $[3,5]$. Among the most significant disadvantages of virtual learning is the fact that instructors and students are separated geographically $[6,7]$. As a consequence, students may feel cut off from their instructors and other students on a social level.

To solve this problem and improve students' educational experiences, virtual learning platforms and learning management systems (LMS) should include rich materials that promote adaptive social engagement with instructors and other students. This study is based on the idea that online learning is essentially social and that social contact with instructors and other students is critical in motivating students to learn and enhancing their satisfaction with online courses $[8,9]$. Online learning and teaching are complex activities with several success indicators. One of the indicators used to assess the quality and effectiveness of online learning is student satisfaction.

There have been multiple student satisfaction studies related to online learning, focusing on areas such as learnerlearner, learner-instructor, and learner-content interaction [10], student engagement [11], faculty satisfaction [12], social presence [8], and overall student satisfaction [13]. Thus, this study will try to examine the critical social factors that could influence the student' satisfaction with online learning.

1.1. Problem Statement. Due to the COVID-19 outbreak, the majority of educational institutions were forced to shift and moved towards online learning [14]. The social distancing caused by the pandemic has resulted in a reduction in several 
social elements such as interactivity, engagement, and support, which considered significant keys in influencing students' satisfaction $[15,16]$. Furthermore, in both face-toface and virtual learning, social elements play a key role in assuring student retention and satisfaction [17]. However, there is limited research regarding the effects of social factors on students' satisfaction with online learning during the COVID-19 pandemic [18]. Therefore, the objective of this study was to contribute to the limited existing body of literature by investigating and modeling the social factors affecting students' satisfaction with online learning.

\section{Literature Review}

2.1. Online Learning Satisfaction. Online learning is used as a complement to face-to-face learning. Some benefits of online learning include simple access to information, appropriate content distribution, content standardization, customized teaching, self-pacing, interaction, and convenience. Although online learning is beneficial to many learners, student satisfaction is required for a successful and effective educational experience. Student satisfaction is an attitude formed as a result of an individual's evaluation of the educational experience, services, and facilities provided [19]. In the context of online learning, satisfaction relies on a wide range of factors, including communication, student participation in virtual conversations, flexibility, workload, technical support, instructional methods, and feedback [20]. Interacting with people, engaging in activities, and receiving feedback help students gain knowledge in a social environment [21].

Several studies have compared student satisfaction and academic outcomes in face-to-face and online courses [22]. However, the results are inconclusive. According to several studies, online learning is exciting for students and produces better learning results than conventional face-to-face learning $[23,24]$. Some other studies found no changes [25], while yet another subset of research shows that online education has a low level of engagement [26]. The factors affecting student satisfaction can be divided into three categories: instructor, interactivity, and technology [27]. While the three factors are interrelated, social factors fall under the category of interactivity. Interaction and technology have impacted student satisfaction, requiring instructors to possess appropriate techno-pedagogical abilities and put in additional effort to engage learners online [28]. Despite the inconclusive findings of the comparison between virtual learning and face-to-face learning outcomes, satisfaction has been found to be positively correlated with academic performance and student engagement.

2.2. Online Learning Satisfaction and the Importance of Social Factors. It is a fundamental human desire to form social bonds. This need also applies to online environments. Individuals seek more than just information; they want to feel connected, supported, and validated even when they are online [29]. Similarly, social elements are present in online learning, and social interactions are essential to the online learning process [4]. Social factors that contribute to student satisfaction include social interaction, social identity, social space, social influence, social presence, and social support $[5,9,30-32]$.

The works of [33] state that in order for e-learning to succeed and produce effective results, student satisfaction is crucial. Furthermore, Rubin et al. [34] expand on earlier research on the community of inquiry [35], highlighting the importance of social, cognitive, and instructional involvement in student learning and satisfaction. The characteristics of learning management systems (LMS) have a substantial impact on community perceptions, according to the inquiry framework. In a similar study, Mahmood et al. [36] found that instructor participation is an essential element in how students perceive virtual learning.

The interaction component is important in both face-toface and online learning modalities [37]. Numerous studies show that in every virtual learning environment, the quantity and quality of student interactions are highly linked to student satisfaction [38-40]. Researchers have discovered, however, that demographic and cultural variables have an impact on the design of appropriate online learning interaction techniques [41]. Social presence is also a significant social factor in virtual learning, as it fosters comfort and emotional ties among students [42] and has been positively linked with learning outcomes and student satisfaction [43]. All these social factors are intertwined and manifest themselves in online learning in social interactions and social presence [44].

2.3. Social Presence (SP). There are ongoing debates regarding what social presence means and how the term is used. In our case, social presence can be defined as how students perceive and build a feeling of connection with teachers, peers, and staff in a virtual environment, through their contact with and the assistance they get from professors and administrative personnel. Online social presence may range from primary contact between people or groups through emails, text messages, and announcement boards to more sophisticated, supervised group work. Engagement techniques may also be used in online teaching and learning to improve social presence and learner retention in online courses $[9,45,46]$. These may include providing more opportunities for social interaction in the class, providing timely feedback, allowing access to everyone, and providing self-assessment opportunities.

Early research on social presence found that students' emotional connections are essential. In virtual learning settings, social presence is a significant determinant of satisfaction and perceived learning [47]. Humor, facial expressions, gestures, tone and speed of verbal expressions, salutations, group allusions, acceptance, and guidance aid student satisfaction and perceived learning. How instructors portray themselves in online classes, how they speak with students, their tones, their emotional displays, and the quality of their interactions with students all add to the sense of social presence [13]. 
To bring social presence to learning, teachers and students must connect to stimulate critical inquiry and guarantee inclusiveness [48]. According to Kehrwald [49], interactions alone do not characterize social presence among students. Still, social presence may be measured using relational presence and the ability to establish connections and sustain ongoing meaningful engagement.

2.4. Social Interaction (SI). The term "social interaction" refers to the interaction that happens between students and instructors when instructors implement strategies to foster interpersonal encouragement and social inclusion [50], as cited in [22]. Lonn et al. [51] outlined three types of social interaction: learner-learner, learner-content, and learnerinstructor. Learner-to-learner interactions take place in a virtual setting, whether or not teachers are present [52]. When students are accessing information via various resources including the social media and Web-based courses, their engagement and academic performance perception will be improved [53, 54]. When an instructor shares data, provides suitable support, elucidates misapprehensions, and escalates student enthusiasm, it is called learner-instructor interaction [22]. These three types of social interaction are important in determining student satisfaction. When different types of interaction are used in the learning environment, satisfaction with the learning experience increases [55]. Multiple forms of interaction may be established by adding extracurricular activities to the academic program.

While student-student interaction is essential for online student satisfaction, the frequency, quality, and timeliness of student-instructor contact are the most significant predictors of student satisfaction [56]. In a study of 120 online graduate nursing students, Thurmond et al. [57] concluded that getting quick feedback from the instructor, choosing evaluation methods, and knowing the instructor all contributed to student satisfaction; these results are consistent with the works of [58]. Researchers found that individuals who gave the most favorable responses about knowing their instructors reported actively engaging in Web-based conversations more frequently.

These findings confirm the importance of encouraging student-instructor interaction to promote active learning. Similarly, in a quantitative study of 186 online graduates, the study [59] discovered a significant statistical link between instructor feedback on completed assignments and learning outcomes, as measured by student satisfaction and overall grades. These results stress the importance of student-instructor contact in student performance and further highlight the importance of satisfaction in online learning.

2.5. Social Space (SS). Social space is the network of social connections among members of a group. It includes groupings of values and norms, rules and responsibilities, beliefs, and aspirations [60]. Social space is also referred to as social climate, online atmosphere, and social environment. Social space benefits from affective aspects of interpersonal relationships in a group, such as group cohesiveness, respect, trust, and belonging [60]. Due to the trust and feeling of community among members, social space affects social interaction, resulting in possibilities for critical discussion where open speech is neither insulting nor destructive. The free flow of information encourages members' devotion to the group's objectives and thus increases overall satisfaction. In conclusion, as Kreijns et al. [60] explain, "a good social space inside the group leads to a positive social climate/ online atmosphere."

The three concepts of social space, sociability, and social presence are interconnected and do not function independently. They affect how social interaction in groups is created and sustained when they work together. According to the research of [61], low sociability in a group has a negative impact on the formation of social space. That is to say, although the two categories involve different aspects of group social interactions, sociability contributes to social space [62].

During asynchronous online conversations, the community members are thought to affect the development of social space [63]. Members may choose to follow the group's objectives or use the learning environment's benefits (i.e., sociability). However, the components of social spaces that influence social space impressions are unclear. Most social presence scholars, unaware of the social space and sociability concepts, use social presence theory, which combines the three aspects into a single "social presence" concept.

2.6. Social Identity (SID). The social identity comprises selfcategorization theory [64] and social identity theory [65]. Social identity can be defined as a person's self-concept concerning their social group membership [65]. Individuals self-identify as members of several social groups or classes $[66,67]$. Individuals use categories to organize and place themselves in their social environments [68], a social and relative approach that leads to in-group and out-group identification [69].

The study of [70] empirically investigated the relationship between students' social identities and their performance in online learning and found that online learning performance affects students' social identities. Their research also emphasizes that students' social identities should be improved to enhance online learning performance and satisfaction.

Social identification increases in-group homogeneity [71], which improves social ties inside a group, as well as individual students' commitment to studying, school performance, and satisfaction with their curriculum and organization. Students who achieve their learning goals are likely to be satisfied with their program and institution [72]. Considering that learning is an identity experience that affects an individual and what he or she can achieve, learning and social identification are intimately connected [73].

Students arrive at college with an academic self-concept, or a belief in their own academic competence. Learners who achieved high-grade point averages in high school tend to have a great academic self-construct, linked to outstanding goal achievement [74]. Students who enroll in postgraduate schools with a strong track record of work experience, for 
example, as a junior or midrange manager, have similar social identity traits [75]. Seeing oneself as a "proven" manager may form a significant part of one's personality, influencing one's interactions with students and instructors.

2.7. Social Influence (SIN). Social influence is defined as the process through which the presence or activity of others influences someone's beliefs, attitudes, or conduct. The four elements of social influence include compliance, obedience, conformity, and minority influence. Fishbein and Ajzen [76] developed the theory of reasoned action (TRA) as a model for explaining how social standards of conformity, identification, and compliance may influence conduct. They named these social effects "subjective norms" and showed that, when coupled with individually held beliefs, they could be utilized to predict behavior. Students' subjective norms are the influences they feel from teachers, other students, or important individuals in the learning environment to adopt the system.

The subjective norm construct indicates that students are influenced by others in their usage and appropriation of the virtual learning system [77]. The study of [78] found that subjective norms affect the frequency with which students utilize ICT in education, based on previous research on the roles of peers and teachers in fostering effective virtual learning. Subjective criteria set by superiors (e.g., parents or employers) have been shown to influence a person's choice to participate in an online program [79]. According to the research of [80], the participation of the instructor and social influence among students impact course involvement, student motivation, educational achievement, and views regarding virtual learning platforms.

Certain studies show that peers are important in influencing technology adoption and use pattern habits for e-learning. The research of [81] examined how peer pressure affects academic achievement and perceptions of online learning. Shin's research did not discover a link between performance and peer influence. However, more recent research indicates that students who feel a strong sense of belonging among their fellow students are more satisfied and more likely to continue with virtual learning [82].

2.8. Social Support (SSP). Social support is a three-part construct with many different aspects. It is defined as an activity in which individuals experience, perceive, and express emotional concern, instrumental help, or knowledge via human interaction [83]. The study of [84] described it as "interaction with others that provides students with insight and good learning experience." Demaray et al. [85] defined social support as "information, appraisal, and emotional support that comes from a variety of sources, including instructors, parents, friends, and colleagues that improves student satisfaction." Social support is among the most significant and vital areas of intermediate studies. It is a critical component often utilized in socio-educational and sociopsychological research [86].

The study of Bean [87] believes that close friends and colleagues facilitate social integration into educational institutions. The study of [88] stated that social support improves interpersonal and intergroup relationships. Student satisfaction is positively linked to social support from classmates or relatives [89]. According to [90], students with strong social lives display higher levels of satisfaction.

When students are incorporated into the social environment on campus, their quality of life improves. The research of [91] feels that involving students in various social activities helps them build a positive mindset and supports learning. A lack of social support may make it more difficult to speak for oneself, maintain autonomy, and establish and sustain relationships, all of which can have a major impact on a person's life and learning. Social support for online learners can be achieved through both student-student interactions and student-instructor interactions [30]. Therefore, institutions must play a critical role in building their social lives and exercising social integration as they study and grow.

\subsection{The Influence of Social Factors in Successful Online} Learning. Social factors are often interrelated with instructor support. Students' attributes, technical support, and virtual course design all influence online learning. Tunison and Noonan [92] examined high school students' initial encounters with online courses and found that they saw their online experiences as inspiring and liberating. Although most of the students regarded their instructors as the ultimate source of knowledge, they felt a newfound sense of independence in virtual learning. Students enjoyed their online experiences as a result of this positive impression, which led to favorable outcomes.

Other studies identify student autonomy as a defining feature of virtual learning [93, 94]. Rice [95] found that students found remote learning challenging and alienating: "Even if students are highly driven and self-directed, they may still find the experience lonely, challenging, and disappointing in a distance education environment." The following characteristics of virtual learners impact their learning: communication values, beliefs, and emotions; dedication to group procedures; and interaction abilities [96]. According to Li et al. [97], student characteristics seem to have a significant role in students' satisfaction in online learning.

In addition to the factors mentioned earlier, virtual course design impacts student success in online learning [98], since it affects students' engagement and involvement in courses. Thus, the virtual classroom's design and the students' characteristics influence the students' learning in the virtual classroom, with the three variables influencing students' involvement in the classroom and their views of learning in it. The social atmosphere in online learning has an impact on students' involvement in the virtual classroom and their perceptions of their learning in this setting [44]. At the same time, interactions with the instructor and with classmates have an impact on the social environment [99]. Hence, the aforementioned social factors have been proven to be significant and influential in the online learning environment. Therefore, this study aimed to investigate and model the social factors that could affect students' satisfaction with online learning. 


\section{Research Methodology}

The main objective of this study was to investigate and model the social factors affecting students' satisfaction with online learning. Therefore, the research question was "Could the proposed social factors affect students' satisfaction with online learning?". Based on the extensive literature regarding social factors and related social theories, the proposed factors-namely social presence (SP), social interaction (SI), social space (SS), social identity (SI), social influence (SIN), and social support (SSP)-were investigated and incorporated into the proposed research model to assess students' satisfaction (SAT) with online learning.

3.1. Research Model and Hypotheses. To achieve the research objective, a research model was developed including the six independent factors mentioned above. These factors' direct influence on students' satisfaction was investigated, as depicted in Figure 1. Based on this research model and the proposed social factors, the following assumptions were developed:

(i) H1: social presence is significantly related to students' satisfaction with online learning.

(ii) H2: social interaction is significantly related to students' satisfaction with online learning.

(iii) H3: social space is significantly related to students' satisfaction with online learning.

(iv) H4: social identity is significantly related to students' satisfaction with online learning.

(v) H5: social influence is significantly related to students' satisfaction with online learning.

(vi) H6: social support is significantly related to students' satisfaction with online learning.

3.2. Research Design and Sampling. Due to the nature of research, a quantitative method approach was applied. A survey was the main tool for collecting the research data. The research was conducted at Jouf University during the second semester of the 2020-2021 academic year. This research employs the chain-referral sampling technique to obtain the required sample. A total of 258 responses were obtained after the elimination of uncompleted questionnaires, with a response rate of $90.8 \%$.

3.3. Research Questionnaire Development. It was important to provide the respondents with a clear understanding of the research before organizing the survey questions. Therefore, the questionnaire included the title and purpose of this research. To determine whether the instruments were appropriate to measure the investigated dimensions, face and content validity were assessed and the questionnaire was sent to three instructional technology experts. As most respondents spoke Arabic as their first language, the original English version of the questionnaire had to be translated into Arabic using the "back translation" technique to achieve clarity and meaning similarity. There were two main sections of questionnaire: one section focused on demographic items, and the other focused on the social factors being investigated-namely social presence (SP), social interaction (SI), social space (SS), social identity (SID), social influence (SIN), social support (SSP), and student satisfaction (SAT). Table 1 shows the research factors, related items, and adapted sources.

\section{Data Analysis and Discussion}

The data were analyzed using Analysis of Moment Structures (AMOS 26).

4.1. Profile of Respondents. The research participants included 285 students attending Jouf University during the second semester of the 2020-2021 academic year. $42.2 \%$ of the respondents were male, while $57.4 \%$ were female. Table 2 shows the full frequencies and percentages of the respondents' profiles.

4.2. Descriptive Statistics. An examination of the descriptive statistics of the data showed that all of the items' means were above the midpoint of scale. Using the maximum-likelihood estimation, the data were examined for multivariate and univariate normality using skewness and kurtosis indexes and Mardia's coefficient. The results show that all of the items' skewness and Kurtosis statistics are between the ordinary distribution \pm 2 , where the Kurtosis ranges from -0.37 to 0.81 and skewness from 0.36 to 0.67 [101]. The multivariate normality test of the data also shows normal distribution; Mardia's coefficient is 167.06, which is less than the acceptable cutoff value [102]. Therefore, the requirements of multivariate and univariate normality are met, with no significant violations observed.

4.3. Test of the Measurement Model. To assess the measurement model, confirmatory factor analysis (CFA) was performed with AMOS 26, using the maximum-likelihood estimation technique. Figure 2 shows the diagram of confirmatory factor analysis (CFA).

The aim of conducting CFA is to examine composite reliability (CR), convergent validity, discriminant validity, and standardized factor loadings along with the goodnessof-fit indices of the measurement model. Table 3 shows the results of confirmatory factor analysis (CFA).

The results in Table 3 indicate that the measurement model unstandardized and standardized estimates for all items are significant at the $p<0.001$ confidence level. The standardized factor loadings range from .65 to .98 , which is higher than 0.50 , the level recommended by [103]. The composite reliability (CR) of all items ranges from 0.77 to 0.94 , exceeding the acceptable cutoff level of 0.70 ; this indicates adequate reliability based on the recommendation of Peterson and Kim (2013). The convergent validity was assessed using the average variance extracted (AVE). The results indicate that the AVE ranges from 0.53 to 0.77 , which is above the level of 0.5 recommended by [104]. To assess discriminant validity, the square root of the 


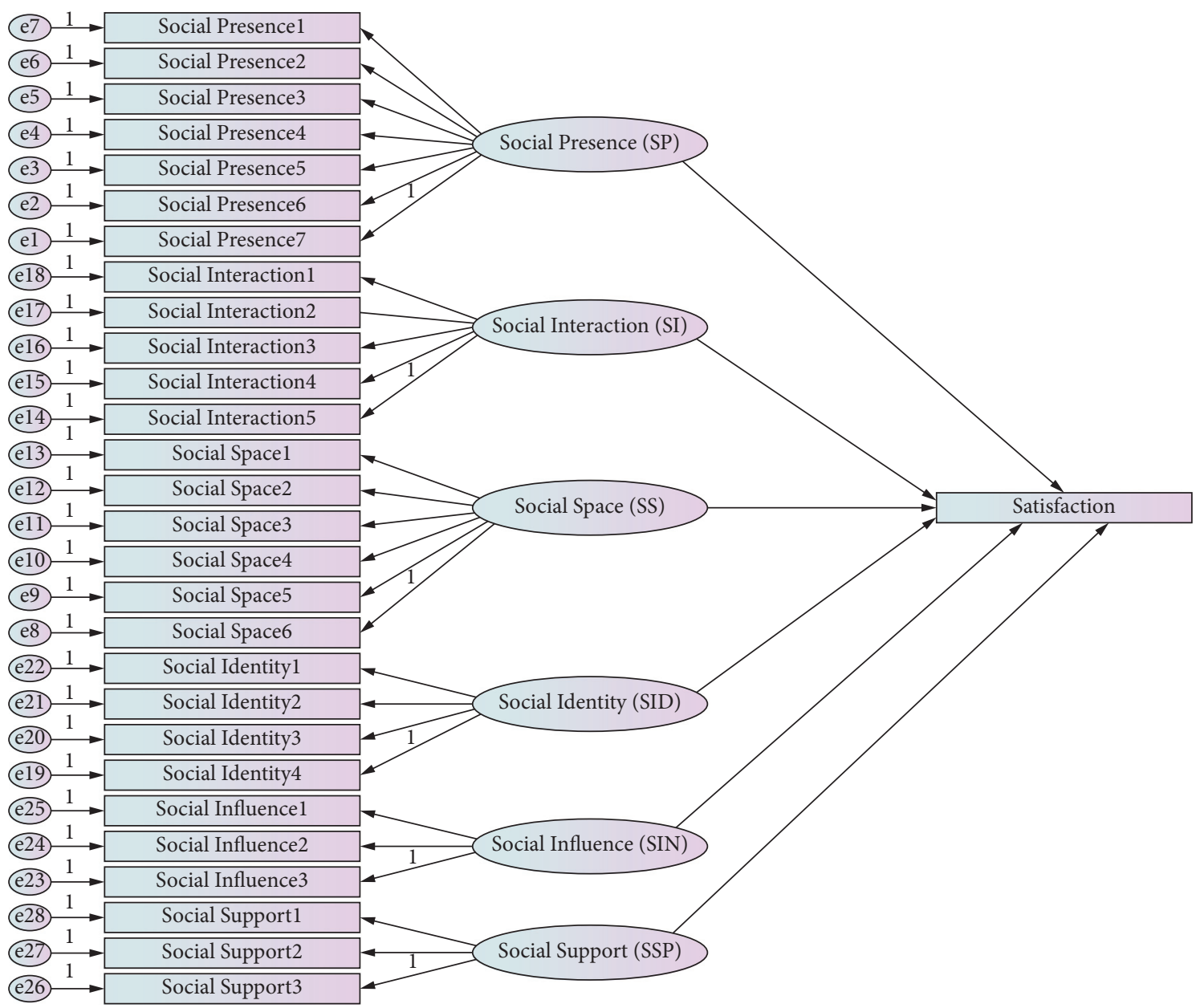

Figure 1: Proposed research model.

TABLE 1: Research factors, items, and adapted sources.

\begin{tabular}{lcc}
\hline Constructs & No. of items & Adapted sources \\
\hline Social presence (SP) & 7 & {$[9]$} \\
Social interaction (SI) & 5 & {$[31]$} \\
Social space (SS) & 6 & {$[60]$} \\
Social identity (SID) & 4 & {$[32]$} \\
Social influence (SIN) & 3 & {$[30]$} \\
Social support (SSP) & 3 & {$[30]$} \\
Satisfaction (SAT) & 9 & {$[100]$} \\
Total & $\mathbf{3 7}$ & \\
\hline
\end{tabular}

average variance extracted (AVE) for each examined factor was compared with its correlation to all other factors. Table 4 indicates the discriminant validity results for the measurement model. The results seem to be satisfactory, as the results of the square roots of the AVEs are above the inter-construct correlation in the correlation matrix [103]. Therefore, the proposed factors in the measurement model are acceptable for further analysis.

As illustrated in Table 5, the results of the goodness-of-fit indices of the measurement model indicate that the chisquare/degree of freedom (CMIN/DF) is 1.758, which is less than the acceptable cutoff limit of 3 [103]. The goodness-offit index (GFI) and comparative fit index (CFI), which are .927 and .954 , respectively, are both above the acceptable
TABLE 2: The frequency and percentage of the respondents' profiles.

\begin{tabular}{lccc}
\hline & Profile & Frequency & Percentage \\
\hline \multirow{2}{*}{ Gender } & M & 109 & $42.2 \%$ \\
& F & 149 & $57.8 \%$ \\
& Science colleges & 63 & $24.4 \%$ \\
& Medical and health colleges & 27 & $10.5 \%$ \\
College & Humanity and management & 73 & $28.3 \%$ \\
& college & $\mathbf{9 0}$ & $\mathbf{3 4 . 9 \%}$ \\
& Education college & 5 & 1.9 \\
Total & Community college & $\mathbf{2 5 8}$ & $\mathbf{1 0 0 \%}$ \\
\hline
\end{tabular}

limit of 0.90. Similarly, the standardized root-mean-square residual (SRMR) is .065, which is below the acceptable maximum of .08. Additionally, the root-mean-square error of approximation (RMSEA) is .059, which is considered acceptable [101, 103]. Overall, the goodness of fit of the measurement model is confirmed, paving the way for additional structural model analysis.

4.4. Test of the Structural Model and Hypotheses. To examine the path analysis of the structural model, the goodness-of-fit indices were inspected using criteria similar to that applied in testing the measurement model $[101,102]$. Table 6 indicates 


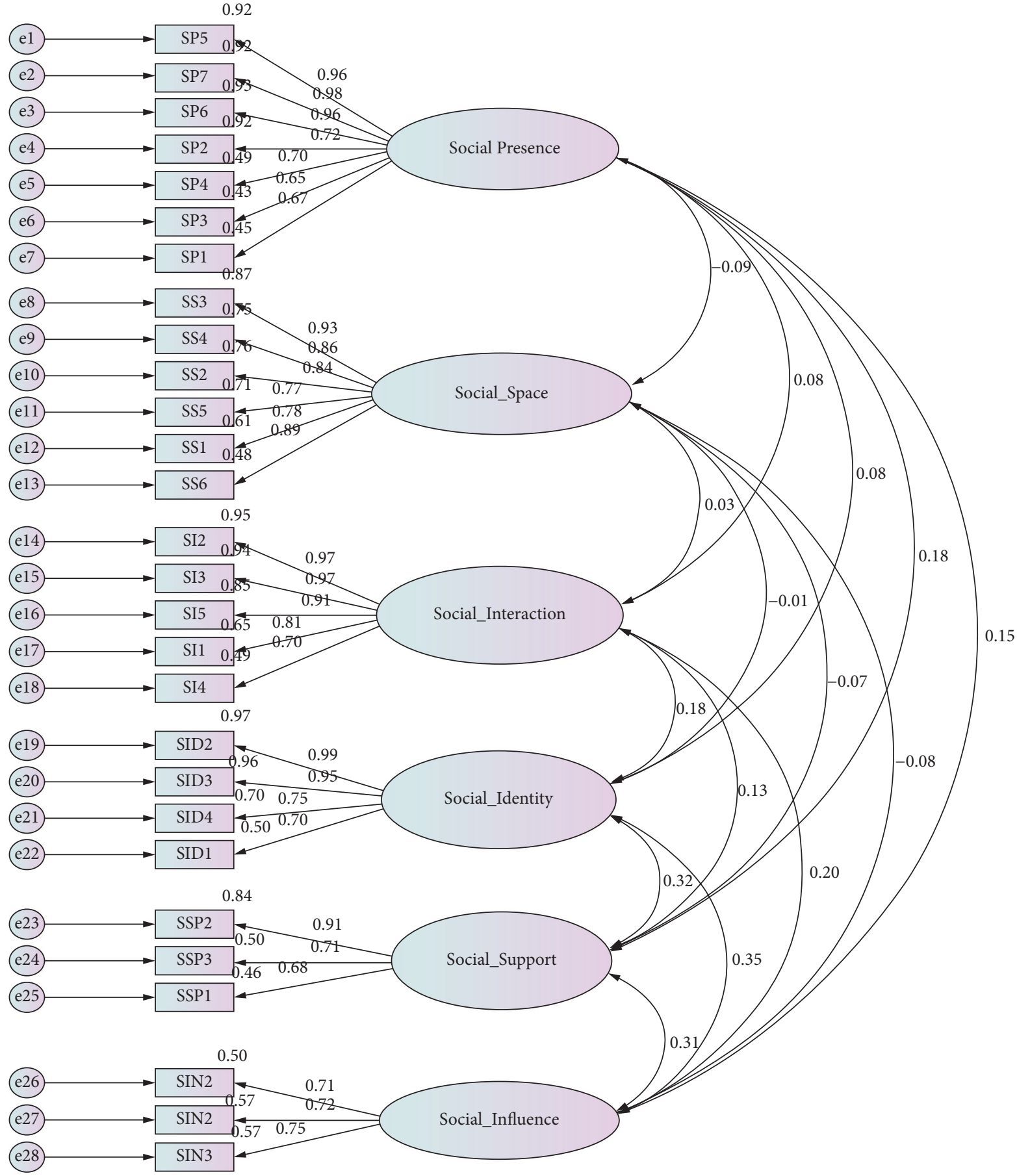

FIgURE 2: Confirmatory factor analysis.

that the structural model indices have a good fit and have achieved the acceptable cutoff level to be considered satisfactory $(\chi 2=599.891 \quad p<0.001, \quad \mathrm{CMIN} / \mathrm{DF}=2.153$, $\mathrm{NFI}=0.911, \quad \mathrm{GFI}=0.942, \quad \mathrm{CFI}=0.943, \quad \mathrm{SRMR}=0.053$, RMSEA $=0.063$ ). Therefore, the path coefficient analysis was performed to examine the significance of the proposed hypotheses. Figure 3 illustrates the path coefficient analysis of the proposed hypotheses in the structural model.

The results of testing the hypotheses, as shown in Figure 3 and Table 7, reveal that all proposed hypotheses were significantly and positively related to students' satisfaction. The proposed model accounted about 56\% of the total variance in students' satisfaction. Interestingly, social interaction is the factor most significantly related to students' satisfaction with online learning $(\beta=0.382, p<0.001)$. However, social presence is also significantly related to students' satisfaction with online learning $(\beta=0.356$, $p<0.001)$, as are social support $(\beta=0.325, p<0.001)$, social space $(\beta=0.279, p<0.001)$, social influence $(\beta=0.243$, $p<0.001)$, and social identity $(\beta=0.203, \quad p<0.001)$. 
TABLE 3: Results of confirmatory factor analysis $(n=258)$.

\begin{tabular}{|c|c|c|c|c|c|c|c|}
\hline Factor & Items & U.E & S.E. & Standardized factor loading & Composite reliability (CR) & Convergent validity (AVE) & $P$ \\
\hline \multirow{7}{*}{ Social presence } & SP5 & 1.000 & & 0.961 & 0.94 & 0.69 & \\
\hline & SP7 & 1.012 & 0.023 & 0.981 & & & $* * *$ \\
\hline & SP6 & 0.998 & 0.025 & 0.965 & & & $* * *$ \\
\hline & SP2 & 0.750 & 0.047 & 0.723 & & & $* * *$ \\
\hline & SP4 & 0.750 & 0.050 & 0.699 & & & $* * *$ \\
\hline & SP3 & 0.663 & 0.050 & 0.683 & & & $* * *$ \\
\hline & SP1 & 0.707 & 0.051 & 0.670 & & & $* * *$ \\
\hline \multirow{6}{*}{ Social space } & SS3 & 1.000 & & 0.932 & 0.92 & 0.66 & \\
\hline & SS4 & 0.948 & 0.046 & 0.855 & & & $* * *$ \\
\hline & SS2 & 0.906 & 0.046 & 0.836 & & & $* * *$ \\
\hline & SS5 & 0.825 & 0.049 & 0.771 & & & $* * *$ \\
\hline & SS1 & 0.860 & 0.050 & 0.780 & & & $* * *$ \\
\hline & SS6 & 0.711 & 0.052 & 0.694 & & & $* * *$ \\
\hline \multirow{5}{*}{ Social interaction } & SI2 & 1.000 & & 0.974 & 0.90 & 0.77 & \\
\hline & SI3 & 0.989 & 0.023 & 0.968 & & & $* * *$ \\
\hline & SI5 & 0.948 & 0.031 & 0.910 & & & $* * *$ \\
\hline & SI1 & 0.856 & 0.042 & 0.806 & & & $* * *$ \\
\hline & SI4 & 0.726 & 0.048 & 0.703 & & & $* * *$ \\
\hline \multirow{4}{*}{ Social identity } & SID2 & 1.000 & & 0.987 & 0.91 & 0.73 & \\
\hline & SID3 & 0.974 & 0.027 & 0.948 & & & $* * *$ \\
\hline & SID4 & 0.782 & 0.045 & 0.749 & & & $* * *$ \\
\hline & SID1 & 0.738 & 0.048 & 0.704 & & & $* * *$ \\
\hline \multirow{3}{*}{ Social support } & SSP2 & 1.000 & & 0.915 & 0.81 & 0.60 & \\
\hline & SSP3 & 0.761 & 0.068 & 0.706 & & & $* * *$ \\
\hline & SSP1 & 0.786 & 0.078 & 0.675 & & & $* * *$ \\
\hline \multirow{3}{*}{ Social influence } & SIN2 & 1.000 & & 0.710 & 0.77 & 0.53 & \\
\hline & SIN1 & 0.967 & 0.106 & 0.716 & & & $* * *$ \\
\hline & SIN3 & 1.075 & 0.122 & 0.752 & & & $* * *$ \\
\hline
\end{tabular}

${ }^{*} p<0.05 ;{ }^{* *} p<0.01 ;{ }^{* * *} . p<0.001$.

TABle 4: Discriminant validity for the measurement model $(n=258)$.

\begin{tabular}{lccccr}
\hline Factors & SSP & SP & SS & SIN & SID \\
\hline SSP & $\mathbf{0 . 7 7 3}$ & & & & \\
SP & 0.179 & $\mathbf{0 . 8 3 3}$ & & & \\
SS & 0.067 & 0.581 & $\mathbf{0 . 8 1 5}$ & $\mathbf{0 . 8 7 8}$ & 0.478 \\
SIN & 0.128 & 0.456 & 0.526 & 0.195 & $\mathbf{0 . 8 5 6}$ \\
SID & 0.323 & 0.389 & 0.405 & & 0.548 \\
SI & 0.306 & 0.151 & 0.279 & $\mathbf{0 . 7 2 6}$ \\
\hline
\end{tabular}

${ }^{*} p<0.05 ;{ }^{* *} p<0.01 .{ }^{* * *} p<0.001$.

TABLE 5: Goodness-of-fit indices of the measurement model.

\begin{tabular}{lcccccc}
\hline & \multicolumn{4}{c}{ Goodness-of--fit indices of the measurement model } \\
\multicolumn{2}{l}{} & CMIN/DF & NFI & GFI & CFI & SRMR \\
\hline $578.468^{* * *}$ & $1.758(<3.00)$ & $0.914(>0.90)$ & $0.923(>90)$ & $0.961(>0.90)$ & $0.061(<0.08)$ & $0.054(<0.08)$ \\
\hline
\end{tabular}

Note: ${ }^{* * *} \cdot p<0.001$.

TABLE 6: Goodness-of-fit indices of the structural model.

\begin{tabular}{|c|c|c|c|c|c|c|}
\hline \multicolumn{7}{|c|}{ Goodness-of-fit indices of the structural model } \\
\hline$x^{2}$ & CMIN/DF & NFI & GFI & CFI & SRMR & RMSEA \\
\hline $599.891^{* * *}$ & $2.153(<3.00)$ & $0.911(>0.90)$ & $0.942(>0.90)$ & $0.943(>0.90)$ & $0.053(<0.08)$ & $0.063(<0.08)$ \\
\hline
\end{tabular}




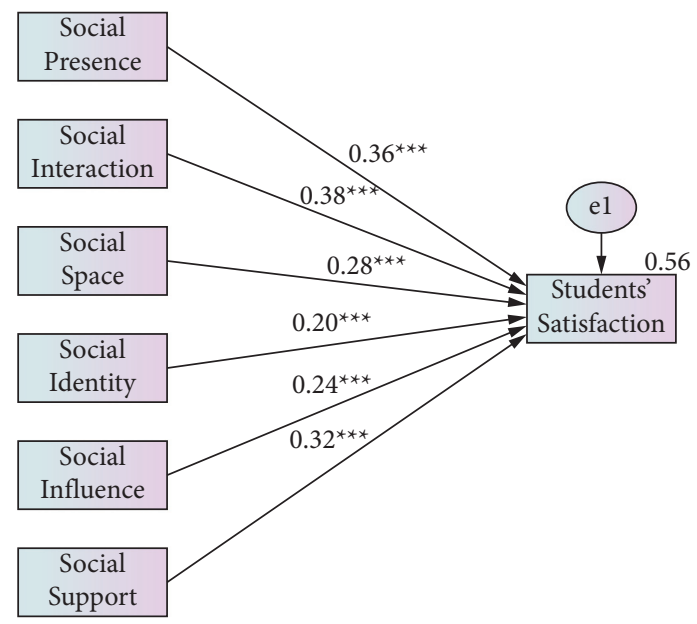

FIgURe 3: Path coefficient analysis of proposed hypotheses.

TABLE 7: Results for the testing hypotheses of structural model.

\begin{tabular}{|c|c|c|c|c|c|c|c|}
\hline $\mathrm{H}$ & Path of hypotheses & $\mathrm{SR} \beta$ & UR & S.E. & C.R. & $P$ & Hypotheses' results \\
\hline $\mathrm{H} 1$ & SAT<---SP & 0.356 & 0.217 & 0.025 & 8.548 & $* * *$ & H1: Supported \\
\hline $\mathrm{H} 2$ & SAT $<---S I$ & 0.382 & 0.246 & 0.027 & 9.187 & $* * *$ & H2: Supported \\
\hline $\mathrm{H} 3$ & SAT $<---S S$ & 0.279 & 0.153 & 0.023 & 6.696 & $* * *$ & H3: Supported \\
\hline $\mathrm{H} 4$ & SAT<---SID & 0.203 & 0.115 & 0.024 & 4.874 & $* * *$ & H4: Supported \\
\hline H5 & SAT $<---S I N$ & 0.243 & 0.124 & 0.021 & 5.831 & $* * *$ & H5: Supported \\
\hline H5 & SAT<---SSP & 0.325 & 0.224 & 0.029 & 7.810 & $* * *$ & H6: Supported \\
\hline
\end{tabular}

SR $\beta$ : standardized regression; UR: unstandardized regression; SE: standard error. ${ }^{* * *} p<0.001$.

Therefore, the examined hypotheses were all considered statistically significant towards students' satisfaction with online learning and were thus accepted.

\section{Discussion}

The main aim of this study is to investigate and model the social factors affecting students' satisfaction with online learning. The results of study reveal that social interaction is the factor that contributes most significantly to students' satisfaction. The findings related to the effects of social interaction are consistent with the findings of previous studies $[3,5,22,52,55,56,58]$. The result of this study also shows that social presence is significantly related to students' satisfaction with online learning. Based on previous research, social presence was expected to be the biggest contributing factor; it was not, although it was significantly related to students' satisfaction to a degree that is consistent with other studies $[9,13,45,46,48]$. As seen in other studies $[30,88,89]$, social support and social influence significantly influenced students' satisfaction. The findings were consistent with other recent research $[80,82]$. Social influence is theoretically related to subjective norms, which have an important relationship with students' satisfaction in an online environment. Furthermore, social space was also significantly related to students' satisfaction. This result confirms Kreijns et al.'s study [60], which stated that "a good social space inside the group leads to a positive social climate/online atmosphere," and supports the results of their recent study [63]. Finally, while social identity shows less of a contribution to students' satisfaction with online learning, it is still significantly related; this finding is consistent with other studies discussing social identity in the learning environment $[69,70,72]$.

\section{Study Implications}

In respect of theoretical implications, the study result revealed that the examined social factors have explained about $56 \%$ of the total variance of students' satisfaction. Thus, examined further social factors are needed by integrating different models and theories related to social context in online learning setting. Furthermore, future research might examine indirect, mediating, and moderation influence of proposed examined factors in this study and other related factors.

On the subject of practical implications, the results indicated that the examined social factors namely social presence, social interaction, social space, social identity, social influence, and social support have shown that significant influence on the students' satisfaction needs to be taken into consideration with the development of online learning. Therefore, the online course designers need to design interactive content that promotes the social interaction and engagement, which would ultimately help the educators prevent the negative absence of social elements in online environment. Furthermore, the administrators of e-learning systems should activate all the features that encourage social communication and engagement between instructors and students to reduce social isolation in the 
online atmosphere. Course designers, administrators, and instructors should take into consideration the importance of social factors when they design and manage online courses to provide a better online learning experience and increase satisfaction and performance.

\section{Conclusion and Limitations}

The study findings shed light on the effects of the proposed social factors on students' satisfaction with online learning. The proposed factors namely social presence, social interaction, social space, social identity, social influence, and social support were found to significantly affect students' satisfaction with online learning. Therefore, social factors are vital to maintain students' satisfaction in an online learning setting. The COVID-19 pandemic has deprived students of face-to-face learning and ultimately reduced the social elements that are considered a significant part of the learning process. Online learning will continue to expand, and therefore, instructors must provide enrichment in online courses with materials that promote social engagement and interaction.

The study has some limitations that need to be addressed in order to provide clear direction for future research. The study is limited by the size of the sample and quantitative methodology. It is also limited by the number of examined social factors, which explain only about $56 \%$ of the total variance of students' satisfaction. Hence, in future research, the proposed factors and instrumentation can be used in studies focused on more universities, either public or private. Researchers could examine additional social factors that may influence students' satisfaction with online learning using qualitative or triangulation methods and ultimately increase the proposed model variance and understanding of students' satisfaction with online learning.

\section{Data Availability}

The data will be available upon request from the author at ar.alenezi@ju.edu.sa. The quantitative data used to support the findings of this study are currently under embargo, while the research findings are commercialized. Requests for data, $6 / 12$ months after publication of this article, will be considered by the author.

\section{Conflicts of Interest}

The authors declare that they have no conflicts of interest.

\section{References}

[1] R. A. Reiser and J. V. Dempsey, Trends and Issues in Instructional Design and Technology, Pearson, Boston, MA, USA, 3rd edition, 2012.

[2] P. R. Lowenthal, "Social presence," in Encyclopedia of Distance Learning, pp. 1900-1906, IGI Global, Hershey, PA, USA, Second edition, 2009.

[3] M. Akcaoglu and E. Lee, "Increasing social presence in online learning through small group discussions," International
Review of Research in Open and Distance Learning, vol. 17, no. 3, pp. 1-117, 2016.

[4] E. Sung and R. E. Mayer, "Five facets of social presence in online distance education," Computers in Human Behavior, vol. 28, no. 5, pp. 1738-1747, 2012.

[5] K. Kreijns, P. A. Kirschner, W. Jochems, and H. Van Buuren, "Measuring perceived social presence in distributed learning groups," Education and Information Technologies, vol. 16, no. 4, pp. 365-381, 2011.

[6] H. Tareen and M. T. Haand, "A case study of UiTM postgraduate students' perceptions on online learning: benefits \& challenges," International Journal of Academic Research in Psychology, vol. 4, no. 6, pp. 86-94, 2020.

[7] M. G. Moore and G. Kearsley, Distance Education: A Systems View of Online Learning, Wadsworth Cengage Learning, Belmont, CA, USA, 3rd edition, 2012.

[8] M. B. Horzum, "Interaction, structure, social presence, and satisfaction in online learning," Eurasia Journal of Mathematics, Science and Technology Education, vol. 11, no. 3, pp. 505-512, 2017.

[9] S. C. Cobb, "Social presence and online learning: a current view from a research perspective," Journal of Interactive Online Learning, vol. 8, no. 3, pp. 241-254, 2009.

[10] E. Alqurashi, "Predicting student satisfaction and perceived learning within online learning environments," Distance Education, vol. 40, no. 1, pp. 133-148, 2019.

[11] J. Paulsen and A. C. McCormick, "Reassessing disparities in online learner student engagement in higher education," Educational Researcher, vol. 49, no. 1, pp. 20-29, 2020.

[12] N. P. Wingo, N. V. Ivankova, and J. A. Moss, "Faculty perceptions about teaching online: exploring the literature using the technology acceptance model as an organizing framework," Online Learning, vol. 21, no. 1, pp. 15-35, 2017.

[13] H. Baber, "Determinants of students' perceived learning outcome and satisfaction in online learning during the pandemic of COVID19," Journal of Education and e-Learning Research, vol. 7, no. 3, pp. 285-292, 2020.

[14] A. S. Al-Adwan, N. A. Albelbisi, O. Hujran, W. M. Al-Rahmi, and A. Alkhalifah, "Developing a holistic success model for sustainable e-learning: a structural equation modeling approach," Sustainability, vol. 13, no. 16, pp. 1-26, Article ID 9453, 2021.

[15] G. J. Longhurst, D. M. Stone, K. Dulohery, D. Scully, T. Campbell, and C. F. Smith, "Strength, weakness, opportunity, threat (SWOT) analysis of the adaptations to anatomical education in the United Kingdom and republic of Ireland in response to the covid-19 pandemic," Anatomical Sciences Education, vol. 13, no. 3, pp. 301-311, 2020.

[16] Y.-M. Cheng, "Students' satisfaction and continuance intention of the cloud-based e-learning system: roles of interactivity and course quality factors," Education \& Training, vol. 62, no. 9, pp. 1037-1059, 2020.

[17] M. K. M. Nasir, "The influence of social presence on students' satisfaction toward online course," Open Praxis, vol. 12, no. 4, pp. 485-493, 2020.

[18] L. P. Dinh and T. T. Nguyen, "Pandemic, social distancing, and social work education: students' satisfaction with online education in Vietnam," Social Work Education, vol. 39, no. 8, pp. 1074-1083, 2020.

[19] W. Elshami, M. H. Taha, M. Abuzaid, C. Saravanan, S. Al Kawas, and M. E. Abdalla, "Satisfaction with online learning in the new normal: perspective of students and faculty at medical and health sciences colleges," Medical Education Online, vol. 26, no. 1, pp. 1-10, 2021. 
[20] H.-C. Wei and C. Chou, "Online learning performance and satisfaction: do perceptions and readiness matter?" Distance Education, vol. 41, no. 1, pp. 48-69, 2020.

[21] A. Bandura, "Social cognitive theory: an agentic perspective," Annual Review of Psychology, vol. 52, no. 1, pp. 1-26, 2001.

[22] L. R. A. Spears, "Social presence, social interaction, collaborative learning, and satisfaction in online and face-to-face courses," https://lib.dr.iastate.edu/cgi/viewcontent.cgi? article $=3983$ and context $=$ etd Doctoral dissertation, Iowa State University, Ames, IA, USA, 2012, https://lib.dr.iastate. edu/cgi/viewcontent.cgi? article $=3983$ andcontext $=$ etd Doctoral dissertation.

[23] R. A. Green, L. Y. Whitburn, A. Zacharias, G. Byrne, and D. L. Hughes, "The relationship between student engagement with online content and achievement in a blended learning anatomy course," Anatomical Sciences Education, vol. 11, no. 5, pp. 471-477, 2018.

[24] E. Riddle and E. Gier, "Flipped classroom improves student engagement, student performance, and sense of community in a nutritional sciences course (P07-007-19)," Current Developments in Nutrition, vol. 3, no. 1, pp. 657-659, 2019.

[25] J. D. Pickering and B. J. Swinnerton, "Exploring the dimensions of medical student engagement with technologyenhanced learning resources and assessing the impact on assessment outcomes," Anatomical Sciences Education, vol. 12, no. 2, pp. 117-128, 2019.

[26] K. L. Krause and H. Coates, "Students' engagement in firstyear university," Assessment \& Evaluation in Higher Education, vol. 33, no. 5, pp. 493-505, 2008.

[27] M. Kurucay and F. A. Inan, "Examining the effects of learnerlearner interactions on satisfaction and learning in an online undergraduate course," Computers \& Education, vol. 115, pp. 20-37, 2017.

[28] A. Yildiz, "The factors affecting techno-pedagogical competencies and critical thinking skills of preservice mathematics teachers," MOJES: Malaysian Online Journal of Educational Sciences, vol. 5, no. 2, pp. 66-81, 2018.

[29] R. L. Shearer, T. Aldemir, J. Hitchcock, J. Resig, J. Driver, and M. Kohler, "What students want: a vision of a future online learning experience grounded in distance education theory," American Journal of Distance Education, vol. 34, no. 1, pp. 36-52, 2020.

[30] I. U. Khan, Z. Hameed, Y. Yu, T. Islam, Z. Sheikh, and S. U. Khan, "Predicting the acceptance of MOOCs in a developing country: application of task-technology fit model, social motivation, and self-determination theory," Telematics and Informatics, vol. 35, no. 4, pp. 964-978, 2018.

[31] C.-W. Wei, N.-S. Chen, and Kinshuk, "A model for social presence in online classrooms," Educational Technology Research \& Development, vol. 60, no. 3, pp. 529-545, 2012.

[32] F. Zeng, L. Huang, and W. Dou, "Social factors in user perceptions and responses to advertising in online social networking communities," Journal of Interactive Advertising, vol. 10, no. 1, pp. 1-13, 2009.

[33] K. Sharma, G. Deo, S. Timalsina, A. Joshi, N. Shrestha, and H. C. Neupane, "Online learning in the face of COVID-19 pandemic: assessment of students' satisfaction at chitwan medical college of Nepal," Kathmandu University Medical Journal, vol. 18, no. 2, pp. 40-47, 2020.

[34] B. Rubin, R. Fernandes, and M. D. Avgerinou, "The effects of technology on the Community of Inquiry and satisfaction with online courses," The Internet and Higher Education, vol. 17, pp. 48-57, 2013.
[35] D. R. Garrison and M. Cleveland-Innes, "Facilitating cognitive presence in online learning: interaction is not enough," American Journal of Distance Education, vol. 19, no. 3, pp. 133-148, 2005.

[36] A. Mahmood, S. T. Mahmood, and A. B. Malik, "A comparative study of student satisfaction level in distance learning and live classroom at higher education level," Turkish Online Journal of Distance Education, vol. 13, no. 1, pp. 128-136, 2012.

[37] Y.-C. Kuo, A. E. Walker, B. R. Belland, and K. E. E. Schroder, "A predictive study of student satisfaction in online education programs," International Review of Research in Open and Distance Learning, vol. 14, no. 1, pp. 16-39, 2013.

[38] F. Martin and D. U. Bolliger, "Engagement matters: student perceptions on the importance of engagement strategies in the online learning environment," Online Learning, vol. 22, no. 1, pp. 205-222, 2018.

[39] K. F. Hew, X. Hu, C. Qiao, and Y. Tang, "What predicts student satisfaction with MOOCs: a gradient boosting trees supervised machine learning and sentiment analysis approach," Computers \& Education, vol. 145, pp. 1-17, Article ID 103724, 2020.

[40] A. W. Cole, L. Lennon, and N. L. Weber, "Student perceptions of online active learning practices and online learning climate predict online course engagement," Interactive Learning Environments, vol. 29, no. 5, pp. 866-880, 2021.

[41] F. González-Gómez, J. Guardiola, Ó. M. Rodríguez, and M. Á. M. Alonso, "Gender differences in e-learning satisfaction," Computers \& Education, vol. 58, no. 1, pp. 283-290, 2012.

[42] J. Weidlich and T. J. Bastiaens, "Designing sociable online learning environments and enhancing social presence: An affordance enrichment approach," Computers \& Education, vol. 142, pp. 1-16, 2019.

[43] C. R. Graham, "Emerging practice and research in blended learning," in Handbook of Distance Education, pp. 351-368, Routledge, Milton Park, Abingdon-on-Thames, Oxfordshire, UK, 2013

[44] A. M. Blaine, "Interaction and presence in the virtual classroom: an analysis of the perceptions of students and teachers in online and blended Advanced Placement courses," Computers \& Education, vol. 132, pp. 31-43, 2019.

[45] S. Joksimović, D. Gašević, V. Kovanović, B. E. Riecke, and M. Hatala, "Social presence in online discussions as a process predictor of academic performance," Journal of Computer Assisted Learning, vol. 31, no. 6, pp. 638-654, 2015.

[46] A. J. Rockinson-Szapkiw, J. Wendt, M. Whighting, and D. Nisbet, "The predictive relationship among the community of inquiry framework, perceived learning and online, and graduate students' course grades in online synchronous and asynchronous courses," International Review of Research in Open and Distance Learning, vol. 17, no. 3, pp. 18-35, 2016.

[47] K. Swan and L. F. Shih, "On the nature and development of social presence in online course discussions," Journal of Asynchronous Learning Networks, vol. 9, no. 3, pp. 115-136, 2005.

[48] H. Zhang, L. Yu, M. Ji et al., "Investigating high school students' perceptions and presences under VR learning environment," Interactive Learning Environments, vol. 28, no. 5, pp. 635-655, 2020.

[49] B. Kehrwald, "Understanding social presence in text-based online learning environments," Distance Education, vol. 29, no. 1, pp. 89-106, 2008. 
[50] I. Jung, S. Choi, C. Lim, and J. Leem, "Effects of different types of interaction on learning achievement, satisfaction and participation in web-based instruction," Innovations in Education and Teaching International, vol. 39, no. 2, pp. 153-162, 2002.

[51] S. Lonn, S. D. Teasley, and A. E. Krumm, "Who needs to do what where?: using learning management systems on residential vs. commuter campuses," Computers \& Education, vol. 56, no. 3, pp. 642-649, 2011.

[52] K. K. Seo and S. Gibbons, Eds., Learning Technologies and User Interaction: Diversifying Implementation in Curriculum, Instruction, and Professional Development, Routledge, Milton Park, Abingdon-on-Thames, Oxfordshire, UK, 2021.

[53] J. A. N. Ansari and N. A. Khan, "Exploring the role of social media in collaborative learning the new domain of learning," Smart Learning Environments, vol. 7, no. 1, pp. 1-16, 2020.

[54] A. Samed Al-Adwan, N. Awni Albelbisi, S. Hasan Aladwan, O. Horani, A. Al-Madadha, and M. Hamdi Al Khasawneh, "Investigating the impact of social media use on student's perception of academic performance in higher education: evidence from Jordan," Journal of Information Technology Education: Research, vol. 19, pp. 953-975, 2020.

[55] T. Miyazoe and T. Anderson, "The interaction equivalency theorem," Journal of Interactive Online Learning, vol. 9, no. 2, pp. 1-6, 2010.

[56] S. D. Penney, "Comparison between faculty and student perception of instructor presence in online courses," Doctoral dissertation, Indiana State University, Terre Haute, IN, USA, 2020.

[57] V. A. Thurmond, K. Wambach, H. R. Connors, and B. B. Frey, "Evaluation of student satisfaction: determining the impact of a web-based environment by controlling for student characteristics," American Journal of Distance Education, vol. 16, no. 3, pp. 169-190, 2002.

[58] R. C. Choe, Z. Scuric, E. Eshkol et al., "Student satisfaction and learning outcomes in asynchronous online lecture videos," CBE Life Sciences Education, vol. 18, no. 4, p. ar55, 2019.

[59] A. Espasa and J. Meneses, "Analysing feedback processes in an online teaching and learning environment: an exploratory study," Higher Education, vol. 59, no. 3, pp. 277-292, 2010.

[60] K. Kreijns, P. A. Kirschner, W. Jochems, and H. Van Buuren, "Determining sociability, social space, and social presence in (A)synchronous collaborative groups," CyberPsychology and Behavior, vol. 7, no. 2, pp. 155-172, 2004.

[61] K. Kreijns, P. A. Kirschner, and W. Jochems, "The sociability of computer-supported collaborative learning environments," Educational Technology \& Society, vol. 5, no. 1, pp. 8-22, 2002.

[62] K. Kreijns, P. A. Kirschner, W. Jochems, and H. Van Buuren, "Measuring perceived sociability of computer-supported collaborative learning environments," Computers \& Education, vol. 49, no. 2, pp. 176-192, 2007.

[63] K. Kreijns, P. A. Kirschner, and M. Vermeulen, "Social aspects of CSCL environments: a research framework," Educational Psychologist, vol. 48, no. 4, pp. 229-242, 2013.

[64] J. C. Turner, M. A. Hogg, P. J. Oakes, S. D. Reicher, and M. S. Wetherell, Rediscovering the Social Group: A SelfCategorization Theory, Basil Blackwell, Hoboken, NJ, USA, 1987.

[65] H. Tajfel, J. C. Turner, W. G. Austin, and S. Worchel, "An integrative theory of intergroup conflict," Organizational Identity: A reader, vol. 56, no. 65, pp. 1-16, 1979.
[66] K. Lund Dean and J. P. Jolly, "Student identity, disengagement, and learning," The Academy of Management Learning and Education, vol. 11, no. 2, pp. 228-243, 2012.

[67] D. Zambo, R. R. Buss, and R. Zambo, "Uncovering the identities of students and graduates in a CPED-influenced EdD program," Studies in Higher Education, vol. 40, no. 2, pp. 233-252, 2015.

[68] W. Kim, O.-R. Jeong, and S.-W. Lee, "On social Web sites," Information Systems, vol. 35, no. 2, pp. 215-236, 2010.

[69] T. Jungert, "Social identities among engineering students and through their transition to work: a longitudinal study," Studies in Higher Education, vol. 38, no. 1, pp. 39-52, 2013.

[70] Z. Mingfang and W. Qi, "Empirical research on relationship between college students' social identity and online learning performance: a case study of Guangdong province," Higher Education Studies, vol. 8, no. 2, pp. 97-106, 2018.

[71] B. K. Ashforth and A. M. Saks, "Socialization tactics: longitudinal effects on newcomer adjustment," Academy of Management Journal, vol. 39, no. 1, pp. 149-178, 1996.

[72] S. Wilkins and A. Epps, "Student evaluation web sites as potential sources of consumer information in the United Arab Emirates," International Journal of Educational Management, vol. 25, no. 5, pp. 410-422, 2011.

[73] E. Wenger, Communities of Practice: Learning, Meaning, and Identity, Cambridge University Press, Cambridge, UK, 1999.

[74] A.-M. Bliuc, R. A. Ellis, P. Goodyear, and D. M. Hendres, "The role of social identification as university student in learning: relationships between students' social identity, approaches to learning, and academic achievement," $E d u$ cational Psychology, vol. 31, no. 5, pp. 559-574, 2011.

[75] S. Wortham, "The interdependence of social identification and learning," American Educational Research Journal, vol. 41, no. 3, pp. 715-750, 2004.

[76] M. Fishbein and I. Ajzen, "Belief, attitude, intention, and behavior: an introduction to theory and research," Philosophy and Rhetoric, vol. 10, no. 2, pp. 177-189, 1975.

[77] R. Panigrahi, P. R. Srivastava, and D. Sharma, "Online learning: adoption, continuance, and learning outcome-A review of literature," International Journal of Information Management, vol. 43, pp. 1-14, 2018.

[78] W. M. Al-Rahmi, A. I. Alzahrani, N. Yahaya, N. Alalwan, and Y. B. Kamin, "Digital communication: information and communication technology (ICT) usage for education sustainability," Sustainability, vol. 12, no. 12, pp. 1-18, 2020.

[79] M. D. Miller, R. K. Rainer, and J. K. Corley, "Predictors of engagement and participation in an on-line course," Online Journal of Distance Learning Administration, vol. 6, no. 1, pp. 1-13, 2003.

[80] J.-E. Oh, Y. K. Chan, and K. V. Kim, "Social media and E-portfolios: impacting design students' motivation through project-based learning," IAFOR Journal of Education, vol. 8, no. 3, pp. 41-58, 2020.

[81] N. Shin, "Transactional presence as a critical predictor of success in distance learning," Distance Education, vol. 24, no. 1, pp. 69-86, 2003.

[82] L. Parte and T. Herrador-Alcaide, "Teaching disruption by COVID-19: burnout, isolation, and sense of belonging in accounting tutors in E-learning and B-learning," International Journal of Environmental Research and Public Health, vol. 18, no. 19, pp. 1-22, 2021.

[83] C. Dunkel-Schetter and K. Brooks, "Nature of social support," in Encyclopedia of Human Relationships, H. T. Reis and S. Sprecher, Eds., pp. 1565-1570, Sage, Thousand Oaks, CA, USA, 2009. 
[84] H. S. Lin, J. C. Probst, and Y. C. Hsu, "Depression among female psychiatric nurses in southern Taiwan: main and moderating effects of job stress, coping behaviour and social support," Journal of Clinical Nursing, vol. 19, no. 15-16, pp. 2342-2354, 2010.

[85] M. K. Demaray, C. K. Malecki, L. M. Davidson, K. K. Hodgson, and P. J. Rebus, "The relationship between social support and student adjustment: a longitudinal analysis," Psychology in the Schools, vol. 42, no. 7, pp. 691-706, 2005.

[86] M. M. Awang, An exploration of strategies used by Malaysian secondary teachers for promoting positive behaviour: professionals and pupils' perspectives, Unpublished $\mathrm{PhD}$. thesis, University of Dundee, Dundee, UK, 2012.

[87] J. P. Bean, "Nine themes of college student retention," in College Student Retention: Formula for Student Success, A. Seidman, Ed., pp. 215-244, ACE \& Praeger, Washington, WA, USA, 2005.

[88] K. J. Topping and J. Foggie, "Interactive behaviours for building independence in exceptional youth," Journal of Research in Special Educational Needs, vol. 8, no. 2, pp. 57-67, 2008.

[89] H. Pluut, P. L. Curşeu, and R. Ilies, "Social and study related stressors and resources among university entrants: effects on well-being and academic performance," Learning and Individual Differences, vol. 37, pp. 262-268, 2015.

[90] S. Ozben, "Social skills, life satisfaction, and loneliness in Turkish university students," Social Behavior and Personality: An International Journal, vol. 41, no. 2, pp. 203-213, 2013.

[91] N. Denson and S. Zhang, "The impact of student experiences with diversity on developing graduate attributes," Studies in Higher Education, vol. 35, no. 5, pp. 529-543, 2010.

[92] S. Tunison and B. Noonan, "On-line learning: secondary students' first experience," Canadian Journal of Education, vol. 26, no. 4, pp. 495-511, 2001.

[93] H. Mısır, D. Koban Koç, and S. Engin Koç, "An analysis of learner autonomy and autonomous learning practices in massive open online language courses," Arab World English Journal, vol. 4, no. 4, pp. 24-39, 2018.

[94] D. U. Bolliger and C. Halupa, "Online student perceptions of engagement, transactional distance, and outcomes," Distance Education, vol. 39, no. 3, pp. 299-316, 2018.

[95] K. L. Rice, "A comprehensive look at distance education in the K-12 context," Journal of Research on Technology in Education, vol. 38, no. 4, pp. 425-448, 2006.

[96] D. Mykota and R. Duncan, "Learner characteristics as predictors of online social presence [Abstract]," Canadian Journal of Education/Revue canadienne de l'éducation, vol. 30, no. 1, pp. 157-170, 2007.

[97] N. Li, V. Marsh, and B. Rienties, "Modelling and managing learner satisfaction: use of learner feedback to enhance blended and online learning experience," Decision Sciences Journal of Innovative Education, vol. 14, no. 2, pp. 216-242, 2016.

[98] M. Hussain, W. Zhu, W. Zhang, and S. M. R. Abidi, "Student engagement predictions in an e-learning system and their impact on student course assessment scores," Computational Intelligence and Neuroscience, vol. 2018, Article ID 6347186, 21 pages, 2018.

[99] J. Lee, P. M. Hernandez, and I. Marshall Jr, "Review of online education in social work programs," Journal of EvidenceBased Social Work, vol. 16, no. 6, pp. 669-686, 2019.

[100] P.-C. Sun, R. J. Tsai, G. Finger, Y.-Y. Chen, and D. Yeh, "What drives a successful e-Learning? An empirical investigation of the critical factors influencing learner satisfaction," Computers \& Education, vol. 50, no. 4, pp. 1183-1202, 2008.

[101] J. F. Hair, R. E. Anderson, B. J. Babin, and W. C. Black, Multivariate Data Analysis: A Global Perspective, Vol. 7, Pearson Upper, , Saddle River, NJ, USA, 2010.

[102] D. George and P. Mallery, "Descriptive statistics," in IBM SPSS Statistics 23 Step by StepRoutledge, Milton Park, Abingdon-on-Thames, Oxfordshire, UK, 2016.

[103] R. E. Schumacher and R. G. Lomax, A Beginners Guide to Structural EquationModeling, Routledge, New York, NY, USA, 4th edition, 2016.

[104] C. Fornell and D. F. Larcker, "Structural equation models with unobservable variables and measurement error: algebra and statistics," Journal of Marketing Research, vol. 18, no. 3, pp. 382-388, 1981. 